\title{
Effectiveness of a Home-Based Postal and Telephone Physical Activity and Nutrition Pilot Program for Seniors
}

\author{
Andy H. Lee, ${ }^{1}$ Jonine Jancey, ${ }^{1}$ Peter Howat, ${ }^{1}$ Linda Burke, ${ }^{1}$ Deborah A. Kerr, ${ }^{1}$ \\ and Trevor Shilton ${ }^{2}$ \\ ${ }^{1}$ School of Public Health, Curtin Health Innovation Research Institute, Curtin University of Technology, GPO Box U1987, Perth, \\ WA 6845, Australia \\ ${ }^{2}$ Western Australia Division, National Heart Foundation, Perth, WA 6008, Australia
}

Correspondence should be addressed to Andy H. Lee, andy.lee@curtin.edu.au

Received 3 March 2010; Accepted 5 May 2010

Academic Editor: Eric Doucet

Copyright (C) 2011 Andy H. Lee et al. This is an open access article distributed under the Creative Commons Attribution License, which permits unrestricted use, distribution, and reproduction in any medium, provided the original work is properly cited.

\begin{abstract}
Objective. To evaluate the effectiveness of a 12-week home-based postal and telephone physical activity and nutrition pilot program for seniors. Methods. The program was delivered by mailed material and telephone calls. The main intervention consisted of a booklet tailored for seniors containing information on dietary guidelines, recommended physical activity levels, and goal setting. Dietary and walking activity outcomes were collected via a self-administered postal questionnaire pre- and postintervention and analysed using linear mixed regressions. Of the 270 seniors recruited, half were randomly selected for the program while others served as the control group. Results. The program elicited favourable responses. Postintervention walking for exercise/recreation showed an average gain of 27 minutes per week for the participants in contrast to an average drop of 5 minutes for the controls $(P<.01)$. Little change was evident in errand walking for both groups. The intervention group $(n=114)$ demonstrated a significant increase in fibre intake $(P<.01)$ but no reduction in fat intake $(P>.05)$ compared to controls $(n=134)$. Conclusions. The participants became more aware of their health and wellbeing after the pilot program, which was successful in increasing time spent walking for recreation and improving fibre intake.
\end{abstract}

\section{Introduction}

It is estimated that the mean energy intake of Australians increased by almost 4\% from 1983 to 1995 [1]. Similar significant increases were observed in the USA between 1971 and 2000 [2]. Worldwide, diet trends have shifted towards an increased consumption of fats and saturated fats, with the level of total fat consumed now exceeding recommended levels of below $30 \%$ of the daily energy intake [3].

Diets high in fruits, vegetables, and dietary fibre are associated with lower rates of obesity and certain cancers [4]. Fruits and vegetables provide a good source of dietary fibre. Throughout the world, reported fruit and vegetable consumptions are now well below the World Health Organization's recommended levels [5]. In the USA, the consumption of fruits and vegetables declined between 1994 and 2005, with only $24.7 \%$ of the adult population consuming fruit or vegetable or both, five or more times a day [6]. Of American adults aged 65 years and over, only $45.9 \%$ consume fruit two or more times a day and $33.7 \%$ consume vegetables three or more times a day [7]. In Australia, even after extensive social marketing campaigns promoting vegetable and fruit consumption, only $16 \%$ and $63 \%$ of older adults met recommended consumption levels for vegetables and fruits, respectively [8], while in Britain, the average intake of fruits and vegetables is estimated at three servings a day [5].

The nutritional requirements of older adults are different from those of younger adults [4], yet relatively few nutritional education programs have been specifically aimed at the elderly population group [9]. The Dietary Guidelines for Americans [10] recommend dietary supplementation of certain vitamins $\left(\mathbf{B}_{12}\right.$ and $\left.\mathrm{D}\right)$, monitoring salt and alcohol intake, particularly its interaction with prescribed and over-the-counter medications, and participation in regular suitable physical activity. The Dietary Guidelines for Older 
Australians [4] also acknowledges the different requirements of older adults, recommending four to seven servings of vegetables and two to three servings of fruit daily. These guidelines also advocate the reduction of both dietary fat and refined carbohydrate to achieve appropriate balance in macronutrient intake necessary for an acceptable body weight at this age range.

The benefits of regular physical activity for older adults are well documented. Apart from reducing obesity, it is associated with an increase in longevity and a decreased risk of many common diseases [11-13]. Studies with followup periods of up to 14 years have shown that sedentary older adults have greater risk of functional decline than those who are physically active $[13,14]$, confirming the contribution of physical activity to postponing disability and improving survival. Physical activity has been shown to enhance psychological and emotional wellbeing [15-17], as well as increasing satisfaction with life [18]. There is also evidence that it can improve quality of life by lowering levels of psychological distress and negative moods [19-21].

The published outcomes from interventions aimed at increasing older adults' physical activity levels are variable. Tailored programs have been found to be beneficial [22], whereas some home-based programs have demonstrated greater adherence than facility-based programs [23]. It has been reported that self-directed programs with some professional guidance, and programs that had four or more contacts between staff and participants, led to significant benefits [23]. Meanwhile, some low cost interventions, such as telephone counselling and video education, are able to increase physical activity in older sedentary females [24].

Interventions that aim to promote both physical activity and healthy nutrition in older adults have identified the effectiveness of written information for promoting behaviour change $[25,26]$. Specific health contracts involving both the health professional and the participant are found to induce positive changes in physical activity and nutrition behaviour [27]. Health log books, where older adults identify health concerns and record how they can be addressed, have encouraged the adoption of health enhancing behaviours [28].

Health programs are clearly needed to help people understand and adopt health enhancing behaviours. However, the literature have reported relatively limited health promotion and nutrition education programs for older adults [9] and few home-based physical activity programs [29]. There is substantial scope for further development of effective strategies for older people to learn how to integrate healthy nutrition and physical activity choices into their every day life to minimise the adverse physiological changes associated with ageing $[26,30,31]$. In this paper, a Physical Activity and Nutrition for Seniors (PANS) program was piloted over a 12week period. A mailed booklet supported by motivational telephone calls formed the main intervention. The objective of this paper is to evaluate the effectiveness of this PANS intervention for home-based 65-74 year old adults in Perth, Western Australia. A survey was conducted at both pre- and Postintervention to assess behavioural changes in walking activity and dietary outcomes.

\section{Methods}

2.1. Participatory Action Research Approach. The development of the PANS intervention was based on a participatory action research (PAR) approach involving systematic investigation and collaboration with the target group [32]. PAR is a form of experimental research in which the researchers and participants are partners in developing the question, intervention, and evaluation. It embraces the principles of participation, reflection and empowerment of individuals seeking to improve their situation. The process helps ensure that health promotion interventions are more relevant to the target group's needs. In the PANS program, the seniors were engaged in the development of the intervention throughout the whole process from early formative research, discussing the intervention type and its implementation, testing it and finally participating in program evaluation of its effectiveness. The PAR approach was appropriate because the program so developed was directly relevant to the older adults and it empowered them through the process of constructing and using their own knowledge.

Underpinned by the PAR approach, any effective intervention should be tailored to suit the seniors and be interactive in order to engage them. As older adults have life experiences, knowledge and habits formed over a long period of time, self help methods and advice in the form of a booklet appeared to be suitable [33]. Focus groups were conducted as part of the PAR approach to inform the appropriate level of intervention. Another component was the provision of health information that specifically addressed the seniors' concerns.

\subsection{Sampling and Recruitment Procedure. Five hundred} seniors residing within metropolitan Perth, the capital of Western Australia, were randomly selected from the Australian Federal Electoral roll which contains the name, age and address of Australian citizens over 18 years of age. Their names were matched to the Perth Electronic White Pages of telephone numbers ( $85 \%$ success rate). On initial phone contact, prospective subjects were required to be aged 65 to 74 years and were excluded if they considered themselves as too active or unhealthy. "Too active" was defined as "30 minutes or more of moderate physical activity on at least 5 days per week," while "unhealthy" referred to "participation in a low stress exercise program would place the person at risk or exacerbate any existing health condition". The PANS program was designed and developed for people at retirement age. The limit of 74 years was imposed to avoid the recruitment of subjects with significant health condition(s), who would find the program difficult or inappropriate. Moreover, human research ethics guidelines prohibit the participation of people at risk of adverse health event while exercising. Of the 302 contactable subjects who agreed to participate, $270(89.4 \%)$ satisfied the selection criteria and were recruited into the study. Half the eligible sample was selected by simple randomization for the PANS program while the remaining subjects served as the control group. Written consent was subsequently sought from each participant. A total of 248 subjects (114 
PANS participants and 134 controls) eventually returned the survey questionnaires, giving an overall response rate of $82 \%$. Ethical approval was obtained from the Human Research Ethics Committee of the researchers' institution (approval number HR69/2002).

2.3. Instrument. A self-completed questionnaire was mailed to participants of both groups to collect data at baseline and Postintervention. Nonmonetary incentives (small gifts and vouchers from a variety store) were used to encourage the return of questionnaires. The questionnaire consisted of the following three sections, as well as a post program "exit survey" for the intervention group.

2.3.1. International Physical Activity Questionnaire. The International Physical Activity Questionnaire (IPAQ) has undergone extensive reliability and validity testing and has acceptable measurement properties for use in population studies of physical activity participation [34]. In this paper, the short self-administered version containing seven items was adopted. The instrument measured frequency (times and days) and duration (minutes) per week of "walking for recreation or exercise," "walking for errands," and "other moderate physical activity" which lasted for at least 10 minutes. Examples of moderate activities included swimming, dancing and cycling at a regular pace. Details of IPAQ are available from http://www.ipaq.ki.se/ipaq.htm. Unlike the full version of IPAQ, "walking for work" was incorporated within "walking for errands" in the short version, since the great majority of participants had already retired from the workforce. The instrument was found to be appropriate to assess walking for Western Australian seniors [35].

2.3.2. Fat and Fibre Barometer. The fat and fibre barometer (FFB) is a self-administered brief food behaviour questionnaire to provide rapid dietary assessment [36]. It contains 20 items to record food eating habits, with 12 questions on fat-related intake (e.g., butter, cheese, processed meat) and 8 questions on fibre-related intake (e.g., fruit, vegetables, cereal). Response values for each item range from 1 representing food behaviour associated with the highest fat or lowest fibre intake, to 5 representing the lowest fat or highest fibre intake. A "not applicable" option is also allowed for some items. The score of each component is then obtained by summing the scores from the corresponding questions. The purpose of the FFB is to classify individuals into ordinal categories according to their fat and fibre intake behaviours and not their actual consumption levels, thus providing a basis for setting dietary change goals. Its reliability, relative validity and usefulness have been demonstrated for the Western Australian population [36].

2.3.3. Demographics and Personal Details. Personal and demographic information was collected, including gender, age, relationship status (with partner; without partner), country of birth (Australia; elsewhere), educational attainment (primary; secondary; tertiary), and self-reported height $(\mathrm{m})$ and weight $(\mathrm{kg})$.
2.4. Exit Survey. The Postintervention survey also collected data on perceived changes in participants' health, wellbeing and fitness attributed to the intervention, intention to be active and maintain a healthy diet, as well as opinion of program components.

2.5. Intervention. The 12-week home-based Physical Activity and Nutrition for Seniors (PANS) intervention was designed by dietitians and physical activity specialists. The major component of the intervention was an interactive booklet that participants received in the mail. The booklet was developed through consultation with the target group. The layout and design of the booklet took into consideration the target audience, for example, larger type font with color illustrations and common nutritional related issues such as constipation.

The booklet advised the participant about physical activity and nutrition and contained information on medical conditions, the benefits of a healthy diet, physical activity guidelines and the Dietary Guidelines for Older Australians [4]. It also provided recipes for healthy eating and suggested opportunities for increasing physical activity especially walking. The participants were invited to identify their own health concerns and how these could be addressed through changes in nutritional and physical activity behaviour. Participants set their own healthy dietary and physical activity goals and were encouraged to record their achievements in the booklet. Further information on the development and evaluation of the interactive booklet were reported in detail elsewhere [37]. This interactive resource was accompanied by printed materials on healthy lifestyle (available from the authors upon request).

The intervention group was also provided with telephone support based on motivational interviewing $[38,39]$. Five weeks following the dissemination of the booklet, the PANS participants were telephoned by final year dietetics students who were trained in motivational interviewing techniques. Each call was about 8 to 10 minutes in duration. The call intended to: (i) check on the participant's goal setting process; (ii) provide positive reinforcement that encouraged continued involvement in the intervention; and (iii) obtain feedback on the program and their use of the booklet. There was also opportunity for questions throughout the 12-week period. In addition, a pedometer was given to each PANS participant to encourage walking.

2.6. Control Group. The control subjects received no program materials. They completed the pre- and Postintervention surveys at the same time as the PANS participants and were similarly provided with small incentives for questionnaire completion.

2.7. Statistical Analysis. Descriptive and inferential statistics were first applied to contrast the demographic profile between the intervention and control groups. The main objective was to assess program effectiveness while accounting for pertinent demographic and confounding factors that 
TABLE 1: Demographic profile of PANS participants and controls.

\begin{tabular}{lcc}
\hline Variable & $\begin{array}{c}\text { Control } \\
\text { group } \\
(n=134)\end{array}$ & $\begin{array}{c}\text { Intervention } \\
\text { group } \\
(n=114)\end{array}$ \\
\hline $\begin{array}{l}\text { Age: mean (SD) years } \\
\text { Height: mean (SD) m }\end{array}$ & $\begin{array}{c}7.74(2.89) \\
\text { Weight: mean (SD) kg }\end{array}$ & $72.19(3.35)$ \\
$\begin{array}{l}\text { Body Mass Index: mean } \\
\text { (SD) kg/m }\end{array}$ & $27.00(4.50)$ & $1.63(0.10)$ \\
$\begin{array}{l}\text { Gender: male } \\
\text { Relationship status: with } \\
\text { partner }\end{array}$ & $48(36 \%)$ & $38.37(13.95)$ \\
$\begin{array}{l}\text { Country of birth: } \\
\text { Australia }\end{array}$ & $89(66 \%)$ & $72(63 \%)$ \\
$\begin{array}{l}\text { Education: primary } \\
\text { school }\end{array}$ & $89(66 \%)$ & $80(70 \%)$ \\
$\begin{array}{l}\text { secondary/high school } \\
\text { tertiary/college }\end{array}$ & $14(10 \%)$ & $10(9 \%)$ \\
\hline
\end{tabular}

could affect behavioural changes. The outcomes of interest were "recreation/exercise walking" (minutes per week), "errand walking" (minutes per week), "fat intake score" and "fibre intake score" at baseline and Postintervention. The repeated measures data were analysed using linear mixed regression models with random (subject) effects to account for the inherent correlation of observations collected from the same individual, thus avoiding misleading inferences due to violation of the independence assumption. Differences between subjects as a source of extra random variation were accommodated with adjustments made in the regression coefficients and corresponding standard errors. Logarithmic transformation was also applied to the two walking variables due to their positively skewed distributions. All statistical analyses were undertaken using the SPSS package version 15.

\section{Results}

Table 1 shows the demographic profile of the intervention and control subjects at baseline. No significant difference in demographic characteristics was found between the two groups $(P>.05)$. The mean age of subjects was 72 years. Two-thirds were female, born in Australia and lived with a partner. The great majority of subjects $(90 \%)$ had attained secondary (high) school education and beyond.

Comparisons of the four main outcomes between PANS participants and controls are summarised in Table 2. Both groups were similar in terms of dietary and walking variables at baseline. However, there were significant differences in fibre intake and recreation/exercise walking between the groups Postintervention. Paired $t$-test further indicated a significant increase in mean fibre intake in the intervention group $(P=.03)$ but little change in the control group $(P=$ $.51)$. On average, there was a significant gain of 27 minutes per week of walking for recreation among PANS participants after the intervention $(P=.02)$, in contrast to a small drop of 5 minutes per week for recreational walking among the controls $(P=.54)$. However, there was no change in fat intake in both groups over the 12 -week period $(P>.1)$. Regarding time devoted to walking for errands, although the control subjects registered an average drop of almost 10 minutes per week, the intervention group exhibited only a negligible increase in errand walking, and no statistically significant differences were evident between $(P=.07)$ and within $(P>.1)$ groups after the program concluded.

Table 3 provides results of mixed regression analyses which controlled for the possible effects of demographic factors. Here, body mass index (BMI) was calculated as the self-reported weight in kilograms divided by height in meters squared. Firstly, subject heterogeneity contributed to the bulk of the residual variability, with estimated intraclass correlation ranged between $41 \%$ and $77 \%$, thus justifying the usefulness of fitting random effects models to the repeated measures data. Secondly, the multivariate analyses confirmed the above univariate results, and demonstrated that PANS participants achieved a significant increase in fibre intake but not fat reduction when compared with seniors not on the program. At the same time, PANS led to a significant increase in walking for recreation amongst program participants, but produced little impact on improving their behaviour in terms of walking for errands. Thirdly, BMI, age and other demographic variables were found to have no significant influences on the dietary and walking outcomes.

Results from the exit survey are summarised in Table 4. The program elicited favourable (agree/strongly agree) reactions from the PANS participants. In particular, the seniors found the program and materials motivating and appropriate. A majority of them became more aware of their health and wellbeing, and claimed to continue to maintain a healthy diet and be more active after PANS. However, less participants $(<50 \%)$ perceived the program as successful in terms of setting and achieving nutritional and physical activity goals, while only a quarter of seniors reported they had become involved in new activities.

\section{Discussion}

A better understanding of the health related needs of the older population can make health promotion programs more relevant [40]. When developing interventions special characteristics of seniors must be considered [41]. Including the target group in the program development and embracing their knowledge and experience are important features of a successful intervention [42]. An important principle underpinning PANS was the close interaction with the target group using elements of Participatory Action Research. The target group took part in focus groups to develop the main booklet, completed self-administered questionnaires, and were consulted on an individual basis throughout the intervention period. The combination of both print materials and motivational phone calls led to a suitable intervention, as confirmed by the positive feedback from the exit survey.

A high response rate of $82 \%$ was obtained as a result of our recruitment and retention strategy based on supportive 
TABLE 2: Comparison of outcomes between PANS participants and controls.

\begin{tabular}{|c|c|c|c|c|c|}
\hline \multirow{2}{*}{ Outcome } & \multicolumn{2}{|c|}{ Control group } & \multicolumn{2}{|c|}{ Intervention group } & \multirow{2}{*}{$\begin{array}{c}t \text { two-sample } \\
t \text {-test }\end{array}$} \\
\hline & Baseline & Post & Baseline & Post & \\
\hline \multirow{3}{*}{ Fibre intake: mean (SD) } & 15.80 & 15.92 & 16.72 & 17.17 & $P_{2}=.06$ \\
\hline & (3.39) & $(3.27)$ & $(2.96)$ & $(3.07)$ & $P_{3}<.01$ \\
\hline & \multicolumn{2}{|c|}{$P_{1}=.51$} & \multicolumn{2}{|c|}{$P_{1}=.03$} & \\
\hline \multirow[t]{2}{*}{ Fat intake: mean (SD) } & $\begin{array}{l}38.71 \\
(5.24)\end{array}$ & $\begin{array}{l}38.65 \\
(5.29)\end{array}$ & $\begin{array}{l}39.13 \\
(4.68)\end{array}$ & $\begin{array}{l}39.36 \\
(4.93)\end{array}$ & $\begin{array}{l}P_{2}=.54 \\
P_{3}=.25\end{array}$ \\
\hline & \multicolumn{2}{|c|}{$P_{1}=.83$} & \multicolumn{2}{|c|}{$P_{1}=.44$} & \\
\hline \multirow[t]{2}{*}{ Recreation/exercise walking: mean $(\mathrm{SD})$ min per week } & $\begin{array}{c}90.76 \\
(107.27)\end{array}$ & $\begin{array}{c}85.49 \\
(98.20)\end{array}$ & $\begin{array}{l}109.95 \\
(90.46)\end{array}$ & $\begin{array}{c}136.58 \\
(111.74)\end{array}$ & $\begin{array}{c}P_{2}=.16 \\
P_{3}<.001\end{array}$ \\
\hline & \multicolumn{2}{|c|}{$P_{1}=.54$} & \multicolumn{2}{|c|}{$P_{1}=.02$} & \\
\hline \multirow[t]{2}{*}{ Errand walking:mean (SD) min per week } & $\begin{array}{c}86.97 \\
(103.55)\end{array}$ & $\begin{array}{c}77.38 \\
(83.89)\end{array}$ & $\begin{array}{c}103.83 \\
(112.35)\end{array}$ & $\begin{array}{c}105.42 \\
(130.30)\end{array}$ & $\begin{array}{l}P_{2}=.25 \\
P_{3}=.07\end{array}$ \\
\hline & \multicolumn{2}{|c|}{$P_{1}=.35$} & \multicolumn{2}{|c|}{$P_{1}=.91$} & \\
\hline
\end{tabular}

$P_{1}$ : baseline versus post paired $t$-test $P$ value.

$P_{2}$ : baseline control versus baseline intervention $P$ value.

$P_{3}$ : post control versus post intervention $P$ value.

TABLE 3: Mixed regression analysis of outcomes before and after PANS intervention.

\begin{tabular}{|c|c|c|c|c|c|c|c|c|}
\hline \multirow[b]{2}{*}{ Parameter } & \multicolumn{2}{|c|}{ Fibre intake } & \multicolumn{2}{|c|}{ Fat intake } & \multicolumn{2}{|c|}{ Recreation/exercise walking $^{\dagger}$} & \multicolumn{2}{|c|}{ Errand walking $^{\dagger}$} \\
\hline & coefficient & $95 \% \mathrm{CI}$ & coefficient & $95 \% \mathrm{CI}$ & coefficient & $95 \% \mathrm{CI}$ & coefficient & $95 \% \mathrm{CI}$ \\
\hline Intercept & 8.74 & $-1.55,19.03$ & 50.12 & $31.99,68.25$ & 1.92 & $-1.13,4.98$ & 0.45 & $-2.46,3.37$ \\
\hline PANS intervention & $1.20^{*}$ & $0.40,1.99$ & 0.71 & $-0.69,2.12$ & $0.45^{*}$ & $0.21,0.68$ & 0.13 & $-0.09,0.36$ \\
\hline Age & 0.11 & $-0.02,0.24$ & -0.14 & $-0.37,0.09$ & -0.01 & $-0.04,0.03$ & 0.01 & $-0.02,0.05$ \\
\hline Body mass index & -0.07 & $-0.14,0.01$ & -0.04 & $-0.18,0.09$ & -0.01 & $-0.03,0.02$ & -0.01 & $-0.03,0.02$ \\
\hline Gender: male & -0.84 & $-1.69,0.01$ & -0.78 & $-2.29,0.72$ & 0.24 & $-0.01,0.49$ & 0.13 & $-0.10,0.37$ \\
\hline With partner & 0.01 & $-0.83,0.84$ & -1.18 & $-2.66,0.29$ & 0.03 & $-0.21,0.28$ & -0.06 & $-0.30,0.17$ \\
\hline Australia born & 0.53 & $-0.31,1.38$ & 0.54 & $-0.95,2.02$ & -0.17 & $-0.42,0.07$ & -0.05 & $-0.28,0.19$ \\
\hline Secondary education & 0.78 & $-0.63,2.20$ & 0.92 & $-1.58,3.42$ & 0.02 & $-0.42,0.45$ & -0.03 & $-0.44,0.38$ \\
\hline Tertiary education & 1.04 & $-0.43,2.52$ & 0.88 & $-1.73,3.48$ & 0.01 & $-0.45,0.45$ & 0.01 & $-0.42, .44$ \\
\hline Intraclass correlation & \multicolumn{2}{|c|}{0.77} & \multicolumn{2}{|c|}{0.85} & \multicolumn{2}{|c|}{0.64} & \multicolumn{2}{|c|}{0.41} \\
\hline
\end{tabular}

${ }^{*} P<.01 .{ }^{\dagger}$ logarithmic transformed. CI: confidence interval.

phone calls and reminders. Nonmonetary incentives (small gifts and vouchers from a variety store) were also used to encourage the return of questionnaires. That the program was home-based with minimal interruptions to daily life reduced barriers to participation, resulting in only a small number of refusals. Moreover, little demand was placed on the control subjects beyond the completion of two short surveys, resulting in their lower level $(0.74 \%)$ of loss to follow-up than the intervention group (16\%). Although the possibility of a Hawthorne effect for the improvement in the PANS group could not be ruled out, the extra attention was planned and was indeed considered as a deliberate part of the intervention.

4.1. Outcomes and Significance. The PANS intervention was found to be effective in increasing the recreation walking time. While walking for exercise or recreation in their neighbourhood appeals to health-conscious seniors who are likely to find other forms of physical exercise more demanding, walking to do errands is a different matter. It normally involves longer distances from home or the need to carry goods and grocery products. Therefore, it would appear difficult to induce the seniors to raise their level of errand walking activity [43].

The PANS intervention appeared to contribute to improving dietary fibre intake. Compared to controls, the program participants recorded a significantly greater increase in fibre intake. The lack of improvement in dietary fat reduction, however, does not necessarily imply that PANS was ineffective. It is possible that a reduction in fat consumption was capped by the "ceiling effect" [44]. The baseline data indicated that the diets of both the intervention group and control group were already relatively low in fat intake. Hence, further reduction in fat was not only unnecessary but also unlikely.

Data from the post intervention exit survey supported the suitability of the program. It is noteworthy that the majority of intervention participants were satisfied and responded favourably to PANS. Most of them $(76 \%)$ underlined the sensitization effect of the program, reporting that as 
TABLE 4: Results of exit survey of PANS participants.

\begin{tabular}{lc}
\hline Response & $\begin{array}{c}\text { Agree/strongly } \\
\text { agree }\end{array}$ \\
\hline $\begin{array}{l}\text { Will still maintain a healthy diet in } 6 \text { months } \\
\text { time }\end{array}$ & $79 \%$ \\
Will still maintain a healthy diet in 12 & $78 \%$ \\
months time & \\
Will continue to maintain a healthy diet & $78 \%$ \\
when program concludes & $76 \%$ \\
Become more aware of health and wellbeing & $76 \%$ \\
Found the PANS program and materials & \\
motivating & $72 \%$ \\
Did not take a long time to read the PANS \\
booklet
\end{tabular}

a consequence they had become more aware of their health and wellbeing. A great proportion (78\%) of participants felt confident they would continue to observe and maintain a healthy diet after conclusion of the program.

4.2. Limitations. Several limitations might compromise the generalizability of the pilot findings. Although the Australian Federal Electoral roll provided a comprehensive database from which to randomly select a representative sample of potential subjects, a 2 : 1 female-to-male ratio for participants was obtained. Males have been shown to be more resistant to recruitment into research studies and walking programs in particular [45]. Self-selection bias was minimised through our randomised study design, but participation was voluntary and reporting bias still posed a threat to the validity of self-reported dietary and physical activity outcomes because of overestimation [46]. Nevertheless, the self-reported data would still be sufficiently reliable for monitoring behavioural changes [47], which formed the basis of our evaluation.
To avoid the festive season, PANS was conducted during spring and restricted to 12 weeks. The duration of the intervention might not be sufficiently long to reflect behaviour change, especially in the case of fat reduction. A longer sustainable program should be considered, though it might increase the likelihood of attrition for seniors.

In this paper, we focused on the assessment of walking activities using IPAQ because responses from initial focus group participants indicated a preference to avoid the sensation of a fast-beating heart. The benefits of walking was emphasised and highlighted in our printed promotional material. A pedometer was given to each PANS participant to encourage walking. Other modes of moderate activities should be considered in future programs.

The fat and fibre barometer, which focuses on habitual fat- and fibre-related food behaviours, is a short and easy to use dietary assessment tool with good reliability. However, a more accurate measure of dietary intake is desirable to determine changes in food and nutrient intake pre- and postintervention.

\section{Conclusions}

The PANS program was specifically tailored for seniors. Its development followed detailed consideration of the literature and careful consultation with the target group. This pilot program provided a practical home-based method for mobilising older people. The participants became more aware of their health and wellbeing after the intervention, which was successful in improving dietary fibre intake and walking for recreation. It is recommended that the PANS intervention be replicated on a larger scale.

\section{Acknowledgments}

The authors are grateful to the seniors who participated in this project and to Dr. Choon-Cheong Leong for his advice on statistical analysis. The research was financially supported by the ATN Centre for Metabolic Fitness.

\section{References}

[1] J. A. Levine and J. M. Miller, "The energy expenditure of using a 'walk-and-work' desk for office workers with obesity," British Journal of Sports Medicine, vol. 41, no. 9, pp. 558-561, 2007.

[2] P. Chanmugam, J. F. Guthrie, S. Cecilio, J. F. Morton, P. P. Basiotis, and R. Anand, "Did fat intake in the United States really decline between 1989-1991 and 1994-1996?" Journal of the American Dietetic Association, vol. 103, no. 7, pp. 867-872, 2003.

[3] S. Kumanyika, R. W. Jeffery, A. Morabia, C. Ritenbaugh, and V. J. Antipatis, "Obesity prevention: the case for action," International Journal of Obesity, vol. 26, no. 3, pp. 425-436, 2002.

[4] National Health and Medical Research Council, Dietary Guidelines for Older Australians, Government Publishing Service, Canberra, Australia, 1999.

[5] A. H. Baker and J. Wardle, "Sex differences in fruit and vegetable intake in older adults," Appetite, vol. 40, no. 3, pp. 269-275, 2003. 
[6] H. M. Blanck, C. Gillespie, J. E. Kimmons, J. D. Seymour, and M. K. Serdula, "Trends in fruit and vegetable consumption among U.S. men and women, 1994-2005," Preventing Chronic Disease, vol. 5, no. 2, pp. 1-10, 2008.

[7] Centers for Disease Control, "Behavioural risk surveillance system," United States, 2005.

[8] A. Daly and L. Roberts, "Collaborative health and wellbeing survey and 2002 health and wellbeing surveillance system: eating, exercise and body size in Western Australian populations," Western Australia: Department of Health, 2000.

[9] N. R. Sahyoun, "Nutrition education for the healthy elderly population: isn't it time?" Journal of Nutrition Education and Behavior, vol. 34, supplement 1, pp. 42-47, 2002.

[10] US Department of Health and Human Services (HHS) and the Department of Agriculture (USDA), Dietary Guidelines for Americans, 6th edition, 2005.

[11] C. J. Crespo, M. R. Palmieri, R. P. Perdomo et al., "The relationship of physical activity and body weight with all-cause mortality: results from the Puerto Rico heart health program," Annals of Epidemiology, vol. 12, no. 8, pp. 543-552, 2002.

[12] J. A. Todd and R. J. Robinson, "Osteoporosis and exercise," Postgraduate Medical Journal, vol. 79, no. 932, pp. 320-323, 2003.

[13] U. Christensen, N. Støvring, K. Schultz-Larsen, M. Schroll, and K. Avlund, "Functional ability at age 75: is there an impact of physical inactivity from middle age to early old age?" Scandinavian Journal of Medicine and Science in Sports, vol. 16, no. 4, pp. 245-251, 2006.

[14] K. Lim and L. Taylor, "Factors associated with physical activity among older people-a population-based study," Preventive Medicine, vol. 40, no. 1, pp. 33-40, 2005.

[15] S. Bozoian, W. Rejeski, and E. McAuley, "Self-efficacy influences feeling states associated with acute exercise," Journal of Sport \& Exercise Psychology, vol. 16, pp. 326-333, 1994.

[16] S. L. Mihalko and E. McAuley, "Strength training effects on subjective well-being and physical function in the elderly," Journal of Aging and Physical Activity, vol. 4, no. 1, pp. 56-68, 1996.

[17] J. Bezner, T. Adams, and L. Whistler, "The relationship between physical activity and indicators of perceived wellness," American Journal of Health Studies, vol. 15, no. 3, pp. 130-138, 1999.

[18] W. J. Rejeski and S. L. Mihalko, "Physical activity and quality of life in older adults," Journals of Gerontology, vol. 56, no. 2, pp. 23-35, 2001.

[19] R. E. Dishman, Exercise Adherence: Its Impact on Public Health, Human Kinetics Books, Champaign, Ill, USA, 1988.

[20] J. G. Spangler and J. C. Konen, "Predicting exercise and smoking behaviors in diabetic and hypertensive patients. Age, race, sex, and psychological factors," Archives of Family Medicine, vol. 2, no. 2, pp. 149-155, 1993.

[21] D. Kritz-Silverstein, E. Barrett-Connor, and C. Corbeau, "Cross-sectional and prospective study of exercise and depressed mood in the elderly," American Journal of Epidemiology, vol. 153, no. 6, pp. 596-603, 2001.

[22] E. V. Cyarto, G. E. Moorhead, and W. J. Brown, "Updating the evidence relating to physical activity intervention studies in older people," Journal of Science and Medicine in Sport, vol. 7, no. 1, pp. 30-38, 2004.

[23] M. Hillsdon, C. Foster, and M. Thorogood, "Interventions for promoting physical activity," Cochrane Database of Systematic Reviews, vol. 1, Article ID CD003180, 2005.
[24] M. A. Nies and T. Partridge, "Comparison of 3 interventions to increase walking in sedentary women," American Journal of Health Behavior, vol. 30, no. 4, pp. 339-352, 2006.

[25] S. E. Doerksen and P. A. Estabrooks, "Brief fruit and vegetable messages integrated within a community physical activity program successfully change behaviour," International Journal of Behavioral Nutrition and Physical Activity, vol. 4, article 12, 2007.

[26] K. Kelley and C. Abraham, "RCT of a theory-based intervention promoting healthy eating and physical activity amongst out-patients older than 65 years," Social Science and Medicine, vol. 59, no. 4, pp. 787-797, 2004.

[27] D. Haber and D. Rhodes, "Health contract with sedentary older adults," The Gerontologist, vol. 44, no. 6, pp. 827-835, 2004.

[28] J. Sheriff and L. Chenoweth, "Promoting healthy ageing for those over 65 with the health check log: a pilot study," Australasian Journal on Ageing, vol. 25, no. 1, pp. 46-49, 2006.

[29] N. Humpel, A. L. Marshall, D. Iverson, E. Leslie, and N. Owen, "Trial of print and telephone delivered interventions to influence walking," Preventive Medicine, vol. 39, no. 3, pp. 635-641, 2004.

[30] W. K. Mummery, G. Schofield, A. Hinchliffe, K. Joyner, and W. Brown, "Dissemination of a community-based physical activity project: the case of 10,000 steps," Journal of Science and Medicine in Sport, vol. 9, no. 5, pp. 424-430, 2006.

[31] W. Kroeze, A. Werkman, and J. Brug, "A systematic review of randomized trials on the effectiveness of computer-tailored education on physical activity and dietary behaviors," Annals of Behavioral Medicine, vol. 31, no. 3, pp. 205-223, 2006.

[32] M. Minkler, "Using participatory action research to build healthy communities," Public Health Reports, vol. 115, no. 23, pp. 191-197, 2000.

[33] G. Egger, R. Spark, J. Lawson, and R. Donovan, Health Promotion Strategies and Methods, McGraw-Hill, Rosehill, Calif, USA, Revised edition, 1999.

[34] C. L. Craig, A. L. Marshall, M. Sjöström et al., "International physical activity questionnaire: 12-country reliability and validity," Medicine and Science in Sports and Exercise, vol. 35, no. 8, pp. 1381-1395, 2003.

[35] J. Jancey, A. Lee, P. Howat, A. Clarke, K. Wang, and T. Shilton, "Reducing attrition in physical activity programs for older adults," Journal of Aging and Physical Activity, vol. 15, no. 2, pp. 152-165, 2007.

[36] J. Wright and J. Scott, "The fat and fibre barometer, a short food behaviour questionnaire: reliability, relative validity and utility," Australian Journal of Nutrition and Dietetics, vol. 57, pp. 33-39, 2000.

[37] L. Burke, P. Howat, A. Lee, J. Jancey, D. Kerr, and T. Shilton, "Development of a nutrition and physical activity booklet to engage seniors," BMC Research Notes, vol. 1, article 77, 2008.

[38] R. K. Martins and D. W. McNeil, "Review of motivational Interviewing in promoting health behaviors," Clinical Psychology Review, vol. 29, no. 4, pp. 283-293, 2009.

[39] S. M. Cummings, R. L. Cooper, and K. M. Cassie, "Motivational interviewing to affect behavioral change in older adults," Research on Social Work Practice, vol. 19, no. 2, pp. 195-204, 2009.

[40] J. S. Lee, E. A. Frongillo Jr., and C. M. Olson, "Conceptualizing and assessing nutrition needs: perspectives of local program providers," Journal of Nutrition for the Elderly, vol. 25, no. 1, pp. 61-82, 2005. 
[41] W. Lin and Y.-W. Lee, "Nutrition knowledge, attitudes, and dietary restriction behavior of the Taiwanese elderly," Asia Pacific Journal of Clinical Nutrition, vol. 14, no. 3, pp. 221-229, 2005.

[42] M. W. Leung, I. H. Yen, and M. Minkler, "Community-based participatory research: a promising approach for increasing epidemiology's relevance in the 21 st century," International Journal of Epidemiology, vol. 33, no. 3, pp. 499-506, 2004.

[43] J. F. Sallis, L. D. Frank, B. E. Saelens, and M. K. Kraft, "Active transportation and physical activity: opportunities for collaboration on transportation and public health research," Transportation Research Part A, vol. 38, no. 4, pp. 249-268, 2004.

[44] P. L. Vreede, N. L. Meeteren, M. M. Samson, H. M. Wittink, S. A. Duursma, and H. J. Verhaar, "The effect of functional tasks exercise and resistance exercise on health-related quality of life and physical activity," Gerontology, vol. 53, no. 1, pp. 12-20, 2006.

[45] J. Jancey, P. Howat, A. Lee et al., "Effective recruitment and retention of older adults in physical activity research: PALS study," American Journal of Health Behavior, vol. 30, no. 6, pp. 626-635, 2006.

[46] C. Gidlow, L. Johnston, D. Crome, N. Ellis, and D. James, “A systemic review of the relationship between socio-economic position and physical activity," Health Education Journal, vol. 65, no. 4, pp. 338-367, 2006.

[47] J. M. Jancey, A. H. Lee, P. A. Howat, A. Clarke, K. Wang, and T. Shilton, "The effectiveness of a physical activity intervention for seniors," American Journal of Health Promotion, vol. 22, no. 5, pp. 318-321, 2008. 


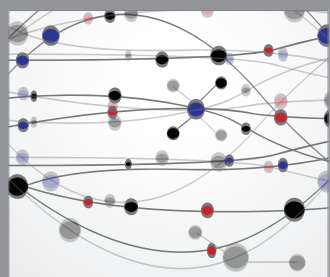

The Scientific World Journal
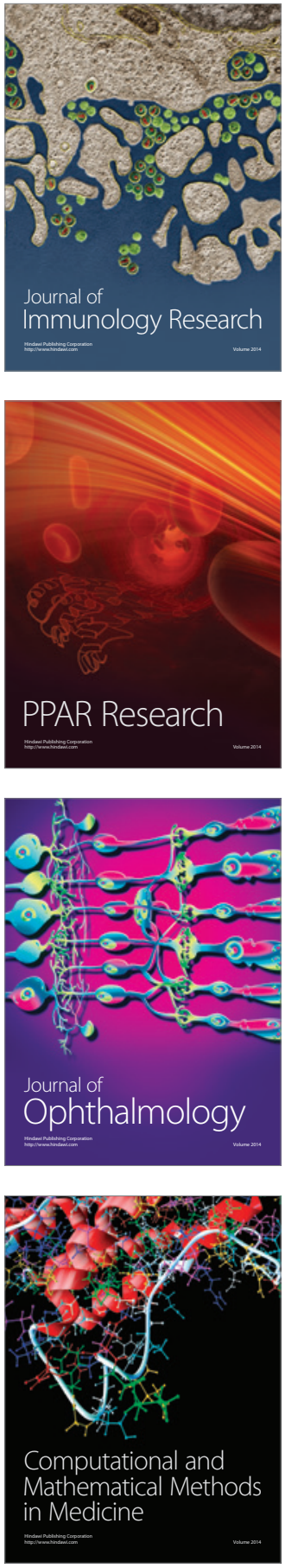

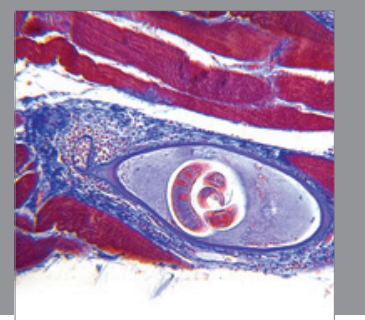

Gastroenterology

Research and Practice
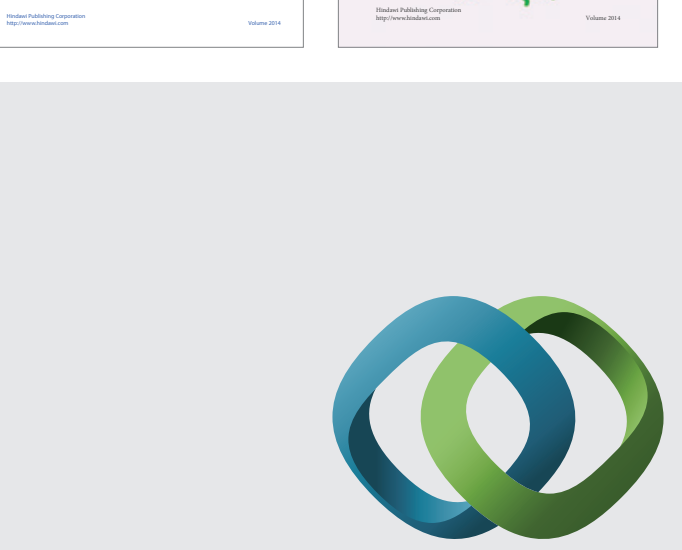

\section{Hindawi}

Submit your manuscripts at

http://www.hindawi.com
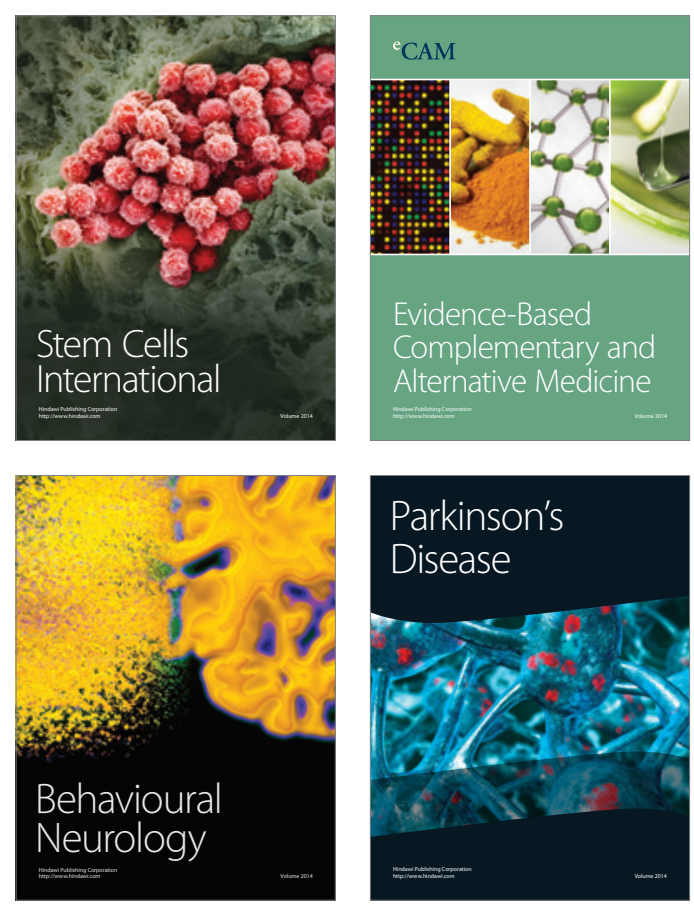

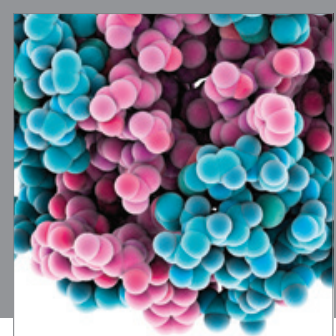

Journal of
Diabetes Research

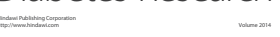

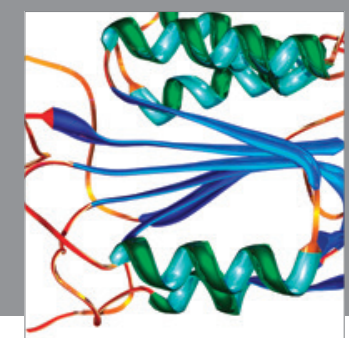

Disease Markers
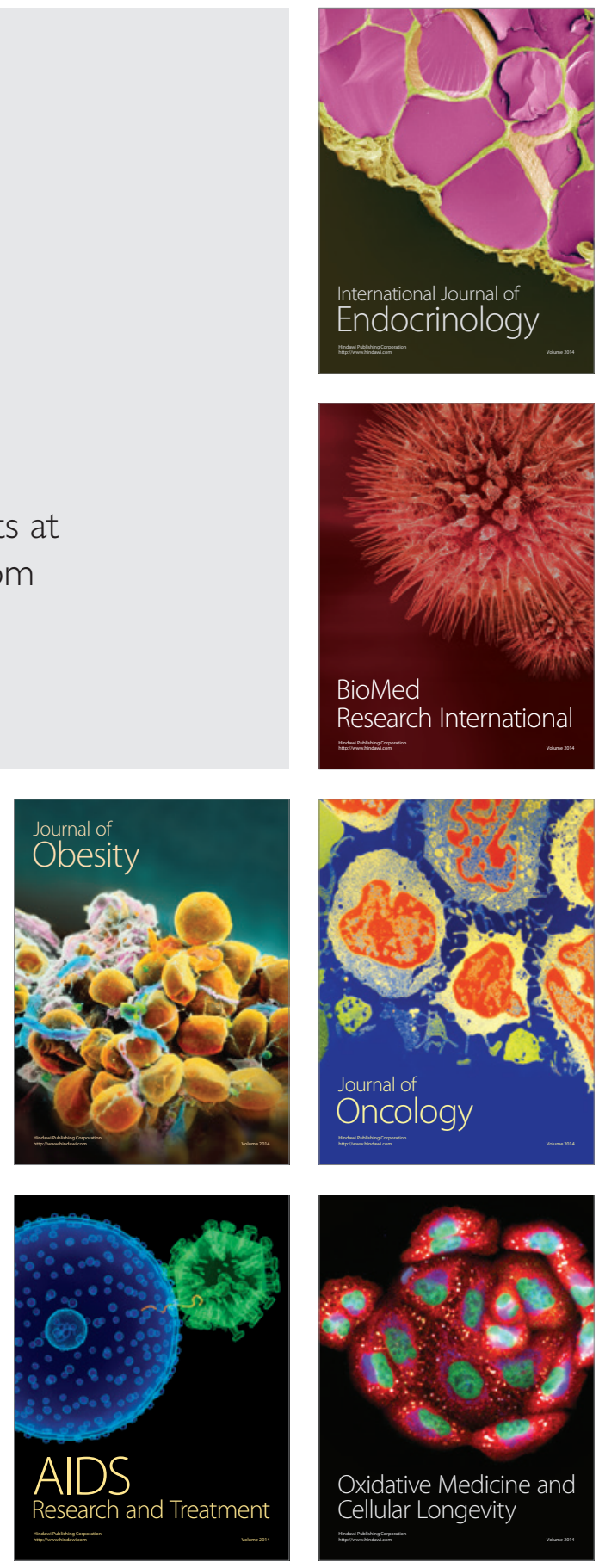